IZA DP No. 7716

Temporary Contracts and Young Workers' Job Satisfaction in Italy

Giovanni S. F. Bruno

Floro E. Caroleo

Orietta Dessy

November 2013 


\title{
Temporary Contracts and Young Workers' Job Satisfaction in Italy
}

\author{
Giovanni S. F. Bruno \\ Bocconi University, Milan \\ Floro E. Caroleo \\ University of Naples "Parthenope", \\ CRISEI and IZA \\ Orietta Dessy \\ Cà Foscari University, Venice \\ and Catholic University, Milan
}

\section{Discussion Paper No. 7716 \\ November 2013}

\author{
IZA \\ P.O. Box 7240 \\ 53072 Bonn \\ Germany \\ Phone: +49-228-3894-0 \\ Fax: +49-228-3894-180 \\ E-mail: iza@iza.org
}

Any opinions expressed here are those of the author(s) and not those of IZA. Research published in this series may include views on policy, but the institute itself takes no institutional policy positions. The IZA research network is committed to the IZA Guiding Principles of Research Integrity.

The Institute for the Study of Labor (IZA) in Bonn is a local and virtual international research center and a place of communication between science, politics and business. IZA is an independent nonprofit organization supported by Deutsche Post Foundation. The center is associated with the University of Bonn and offers a stimulating research environment through its international network, workshops and conferences, data service, project support, research visits and doctoral program. IZA engages in (i) original and internationally competitive research in all fields of labor economics, (ii) development of policy concepts, and (iii) dissemination of research results and concepts to the interested public.

IZA Discussion Papers often represent preliminary work and are circulated to encourage discussion. Citation of such a paper should account for its provisional character. A revised version may be available directly from the author. 
IZA Discussion Paper No. 7716

November 2013

\section{ABSTRACT \\ Temporary Contracts and Young Workers' Job Satisfaction in Italy}

The Italian process of flexibilization of the labour market has created a dual market populated by protected permanent employees and unprotected temporary workers. The latter comprises not only temporary employment relationships but also autonomous collaborations used by firms as low-cost de facto temporary employment relationships. Little is known about the quality of these temporary jobs, particularly widespread among young workers. We estimate a regression model of perceived overall job satisfaction of young workers, based on the ISFOL-PLUS 2006-2008-2010 panel. We control for the various temporary contracts and for perceived satisfactions in nine aspects of the job. We find that lack of job stability is the most serious cause of lower satisfaction for both temporary employees and autonomous collaborators. But while temporary employees compensate concerns of job stability with other job aspects, attaining satisfaction levels comparable to those of permanent employees, autonomous collaborators do not and are thus significantly the least satisfied.

JEL Classification: J28, J81

Keywords: flexicurity, job satisfaction, de facto temporary employment

Corresponding author:

Floro Ernesto Caroleo

Department of Business and Economics Studies

University of Naples "Parthenope"

Via Generale Parisi n. 13, Napoli I-80133 Naples

Italy

E-mail: caroleo@uniparthenope.it 


\section{Introduction}

In recent decades increasing labour market flexibility has been the main response to the high structural unemployment problem in all the OECD countries. Implementation of this goal has followed different strategies in different countries, mainly according to the existing and desired level of Employment Protection Legislation (EPL): in some countries efforts have been made to reduce the degree of EPL of existing permanent contracts, whereas in others the existing high levels of EPL have been joined by new contractual forms of temporary jobs, namely fixed-term and temporary agency work contracts. Rules regulating temporary employment have been liberalized in several Mediterranean, Continental and East European countries. In particular, Germany and Italy have recently relaxed their temporary employment legislation more than others (Jahn et al., 2012).

Such reforms "at the margin" are widely considered the chief way in which unprotected people (youth, women, less skilled) may enter the labour market, especially in the presence of segmented labour markets, and at the very least contribute to increase firms' profits (Boeri, 2011).

There are two related ways to view the potential effects of flexibility. The first, which is more traditional, focuses on the labour market outcomes of flexible contracts. The second view, which has become established more recently, is concerned with the general quality of "new" jobs.

From the former standpoint the desirable outcome in the labour market both for firms and workers is employment stability. Therefore in the empirical literature it has been questioned whether temporary contracts are stepping stones towards a stable occupation or a precariousness trap especially for the weaker players in the labour market (cfr. Bruno et al., 2013 and the literature quoted therein). On the other hand, it has been argued that two-tier reforms have widened the insider-outsider divide making real reforms to deal with the great recession much harder (Bentolila et al., 2012). From the labour market perspective, most of the concerns raised from the widespread use of temporary contracts regard job security, based on the fact that temporary contracts are generally much less protected from job loss than their permanent counterparts. If some countries (such as Denmark and Netherlands) have combined policies of EPL reduction with extending unemployment benefits and introducing active labour market policies, therefore being able to implement the so-called model of flex-security (European Commission, 2007), in others (such as Italy) temporary workers are still mainly an 
unprotected category, such that we might say, in the words of Berton et al. (2009), that a flexinsecurity model has been implemented.

In the last few decades, several international institutions have also considered a different, multidimensional way to evaluate jobs. Indeed, undertakings have been made not only to increase employment but also to improve its quality (the United Nations Millennium Declaration, approved by the UN Assembly in September 2000; ILO, in its school to work transition survey, as explained in Elder, 2010; Lisbon Agenda, 2000; Eurofound, 2012).

In Italy the flexibilization of the labour market has been implemented through the continuous proliferation of new temporary contractual work arrangements of a heterogeneous nature, which increasingly include arrangements peculiar to autonomous work but hide de facto temporary employment relationships. Temporary contracts are widespread among young people. They have been effective in helping the young to enter the labour market, but at the expense of 1) delaying the step to permanent employment, since the rate of permanence in temporary contracts is about $43 \%$; and 2) facilitating the exit to unemployment as an effect of the crisis, since 2007 (Mandrone and Marocco, 2012b).

The question therefore arises as to whether this flexibilization process in Italy, beyond the above effects, has improved the quality of jobs among disadvantaged workers. In this paper we attempt to answer this question, focussing on the quality of jobs among young workers as reflected by their own perceived job satisfaction levels.

To our knowledge, this is the first attempt in this sense on somewhat unexplored territory for Italy, namely that of subjective evaluation of job quality among young workers. Building upon previous studies in other countries (van Praag et al., 2003, for Germany; de Graaf-Zijl, 2012, for the Netherlands; Booth et al., 2002, Bardasi and Francesconi, 2004, and Green and Heywood, 2011, for the UK) we estimate a regression model of self-declared job satisfaction to quantify the relationship between job satisfaction and temporary contract arrangements, and in particular to what extent, for each category of workers, lower satisfaction with one aspect of the job is compensated by higher satisfaction with another aspect.

For our analysis we used the 2006-2008-2010 panel collected by the Institute for Workers' Professional Development (Istituto per lo Sviluppo della Formazione Professionale dei Lavoratori, ISFOL) in the Participation, Labour, Unemployment Survey (PLUS). This data set has a number of advantages for the purposes of our research: 1) it is a panel, and as such it allows us to include individual effects in the specification, which is crucial when working with models of personal evaluation; 2) it covers a time period that is subsequent to the introduction of labour market reforms and that includes the beginning of the financial crisis, 
whose effect on job satisfaction, therefore, can in principle be identified; 3) it follows individuals, albeit bi-yearly, for five years, which is particularly useful given the persistence in temporary contracts of young people in Italy; 4) it allows identification of de facto temporary employment relationships, disaggregated into the two broad categories of temporary employment and autonomous collaborations; 5) it presents a unique wealth of information about self-declared satisfactions on an uncommonly large number of job aspects. More specifically, we observe nine dimensions of job satisfaction, whereas for other countries' data far fewer job aspects are available (four in Green and Heywood, 2011; five in de Graaf-Zijl, 2012). This last feature of ISFOL-PLUS data allows us to estimate a complete model of job satisfaction, in which all the job aspects are used as explanatory variables, both separately and in interaction with the contract dummies.

We find that job stability is the most serious cause of lower satisfaction for both temporary employees and autonomous collaborators. On the other hand, the various categories of temporary contracts respond quite differently to differences in aspect satisfactions. This implies that temporary employees get compensated for dissatisfaction with job stability with more satisfaction from other job aspects, and eventually attain satisfaction levels comparable to those of permanent employees. By contrast, autonomous collaborators are not compensated, and are thus, on average, the least satisfied.

The chapter is organised as follows. In Section 2 we review the literature on the relationship between temporary work and job satisfaction. Section 3 analyses the Italian path to flexibilization of the labour market. In Section 4 we describe our data and define the variables used for the empirical analysis. Section 5 explains our econometric strategy. Results are discussed in Section 6, followed by concluding remarks in Section 7.

\section{Temporary work and job satisfaction}

Job satisfaction is a subjective measure of how people feel about their job. Broadly speaking, it can be thought of as a multidimensional construct involving subjective aspirations and objective opportunities. In this paper we focus on so-called cognitive job satisfaction which is the extent of the individual's satisfaction with particular aspects of their jobs, such as the work environment, work organization, duties, protection against sickness, accident and industrial injury, career perspectives, pay, competence and skills development, and job security.

Although workers' job satisfaction has been widely analysed by sociologists and industrial psychologists it also conveys useful information about economic life and labour market 
decisions that should not be ignored (Freeman, 1978; Eurofound, 2007). From this point of view it is important for at least two reasons: 1) it increases job productivity (Hamermesh, 1997) and therefore firm productivity (Oswald, 1997); and 2) it improves social welfare, as it is extremely closely correlated to overall individual happiness and well-being (social life, family, etc.) (Addabbo and Solinas, 2012).

As we have seen, due to the spread of temporary contracts, the potential effects of flexibility on labour market outcomes have been extensively analysed. However, a growing empirical literature has recently also studied the impact of flexibility on job satisfaction (see, for example, Origo and Pagani, 2009).

Specializing in the economic dimension of job satisfaction, the latter can be considered a proxy of the utility function, and as such is expected to be increasing with wage or income (or at least with income of reference groups) and decreasing with hours of work (Clark and Oswald, 1996), all other conditions being equal. In this case, a lower wage of temporary workers, compared with that of permanent ones, does not mean in theory less job satisfaction but simply that they are discounting the cost of filling the work experience or skills gap and the costs of the time needed to gather information in searching for the best match. According to the stepping stone hypothesis, therefore, the lower satisfaction of temporary workers, found in the majority of empirical research, is nothing else but the motivation driving them towards a stable occupation, which is ranked as one of the most important factors of job satisfaction (European Commission, 2001), or even towards occupations and jobs which ensure the best match between a worker's ability and job requirements, as well as with personal requirements and occupation-specific reward structures (Eurofound, 2007).

We notice, however, that empirical studies show several conflicting findings. According to Booth et al. (2002), for example, temporary workers have a lower satisfaction with several aspects of their jobs in the UK. For the same country, Bardasi and Francesconi (2004) report, on the other hand, no long-term negative effects of limited-duration contracts.

de Graaf-Zijl (2012) studies the case of the Netherlands, analysing different work contracts (regular, fixed-term, on-call, temporary agency) on five job aspects. She finds that a lack of job security is responsible for lower job satisfaction of temporary workers compared to that of permanent workers. However, with the exception of temporary agency workers, the gap disappears if other job aspects are considered, especially job content. Using British data and considering four job aspects Green and Heywood (2011) state the opposite: low job satisfaction associated with less job security is not offset by higher compensation or other job 
characteristics. One possible explanation is lower coverage against job loss in the UK than in the Netherlands.

Clark et al. (1996) provide strong evidence for a U-shaped relationship between age and job satisfaction. Generally, it has been found that women report higher levels of job satisfaction than do men (gender-job satisfaction paradox) despite their disadvantaged position on the labour market (Clark, 1997; Sousa-Poza and Sousa-Poza, 2003; Kaiser, 2007). Holding income constant, satisfaction levels are shown to be strongly declining with the level of education. An important determinant of job satisfaction, concerning in particular temporary youth workers, is overeducation or overskilling (Allen and van der Welden, 2001). Finally, there are also some occupational characteristics that may influence the job satisfaction-work flexibility relation, such as the difference between managers, blue-collar and white-collar workers, and sectors. The self-employed in general report greater overall job satisfaction than employees (Blanchflower, 2000; Bradley and Roberts, 2004).

\section{The Italian case}

In Italy, the flexibilization process of the labour market has followed the path of reforms at the margin, without therefore reducing the degree of EPL for employees working with a permanent job (considered as the "standard" type of contract). A number of new contractual forms for temporary jobs have been introduced in the form of "atypical" or "non-standard" jobs ${ }^{1}$. The first attempt goes back to the 1980 s with the implementation of work-and-training employment contracts, but the main process of labour market flexibilization started in the second half of the 1990s with the so-called Treu reform (Law 196/1007), that introduced temporary work agencies as well as temporary contracts, regulated under Legislative Decree 368 /2001, and redefined the part-time contracts. The reform of the Italian labour market continued with the "Biagi Reform" (Law 30/2003) that introduced other particular contractual forms of non-standard employment such as: job on call, job sharing, job placement agreements and an update of apprenticeship contracts. Other contractual arrangements of labour outsourcing, similar to temporary agency work contracts, were also proposed such as staff leasing and transfer of undertakings.

Labour reforms have also paid special attention to self-employment, considering that it traditionally accounts for a large share of the working population in Italy. Some worker categories have been introduced, such as collaborators, contracting/consulting workers and

1 The concept of "standard" refers to the Fordist model of production in which the work contract of unlimited duration was the typical contractual form regulating work. 
occasional workers, who are contracted to execute specific duties for the firm in a fixed timelimit as free-lancers, coordinated by the employer but not hired as employees. Although formally "autonomous" or self-employed, insofar as their contracts are continuously renewed, such workers become a very low cost for firms to implement their goal of flexibility, thus hiding an employment relationship (lavoro parasubordinato). In other words, although selfemployment could be considered another "typical" form of work, as it is neither of limited duration nor is it a form of dependent employment, in recent years in Italy it has also tended to include unprotected "false" autonomous temporary collaborators that de facto are "nonstandard" or "atypical" employees.

These different trends of flexibilization of the Italian labour market, mixed with an inappropriate use of employment opportunities, especially among young people, have created profound disarray in the employment world. The multilevel segmentation of working relationships has made the traditional categories inadequate to understand the current composition of the Italian labour market. In particular, the distinction between "atypical employees" and "atypical autonomous" workers is crucial for the analysis of employment quality linked to the flexibilization process of the Italian labour market. These two categories not only differ from the contractual point of view, as explained above, but they can also generate different developments of workers' skills, career patterns, relationships with colleagues, time schedules, and (least but not last) wages.

The disaggregation among contracts therefore needs to be sufficiently detailed, as a general classification of working people into permanent employees, temporary employees and the self-employed, including "autonomous collaborators", would be highly distortional in the Italian context. The pattern becomes even more complicated if we consider that the flexibilization of work relationships along the line of free-lance collaborations has recently intensified to the point that in many cases individuals have decided, perhaps pushed by the contractor, to become formally self-employed with their own VAT code, although working only for one firm. This is an even cheaper tool than "atypical autonomous" contracts for firms to implement flexibility, which in some sense 'perturbs' to an even greater extent the definition of the self-employed as "typical" workers.

All of the foregoing reasons help clarify the benefits of the ISFOL-PLUS Panel which, besides providing otherwise unavailable information on personal evaluations of job satisfaction, also gives the opportunity to distinguish the contractually different forms of "typical" and "atypical" jobs, as we explain in the next section. 


\section{Data}

Our empirical analysis is based on micro-data collected by ISFOL in the Participation, Labour, Unemployment Survey (PLUS). This survey, started in 2005, consists in a sample of about 38,000 working-age people interviewed by telephone. Detailed personal data, information about education, family background, occupational characteristics and job search condition are collected. In methodological terms, the representativeness of the sample follows exactly the same criteria as the national survey carried out by the Italian National Institute of Statistics (ISTAT): the Labour Force Survey (LFS). But the general purpose of the PLUS questionnaire is also to record people's self-perceptions about different aspects of their lives, and especially of their jobs, thereby completing the canonical information available in the LFS. In particular, the PLUS allows us to analyse in greater depth both the different contractual forms of workers and their satisfaction with particular dimensions of their job.

In our analysis we use the longest 2006-2008-2010 panel version available for taking advantage of the longest working history of individuals. Classification of the contracts in the long-panel PLUS version allows us to break down de facto temporary employment into its three components of fixed-term contracts, other temporary contracts and autonomous collaborations (Mandrone, 2012).

In our analysis we focus on the population of young working people, selecting the sample of people aged between 15 and 35 years. The choice of this high upper bound for age is due to the evidence that in Italy exit from school/entrance into the labour market is often delayed, and hence the category of young workers is wider than in other countries. The sample does not include immigrants (identified as those without Italian citizenship) and those working for the armed forces. Table 1 reports the distributions of observations by year and sex, both for the whole population and for the sample of workers. The average number of observations per year is 6,700 and the distribution between men and women is constant across years, with young women more numerous than young men (52\% versus $48 \%$ ). This is due to the fact the whole population includes the inactive and the unemployed, where women are highly present. Restricting the sample to the population of the employed, men constitute $55 \%$ and women $45 \%$ on average every year.

\subsection{Evidence on contracts and estimation sample}

In the panel version of ISFOL data, the detailed information about contracts sought in the questionnaire is aggregated into the seven categories shown in Table 2. As explained in 
Section 3, the two main categories of typical jobs in Italy are Permanent Employment (EP) and Autonomous activity (A), including business owners-entrepreneurs, partnerships, and the self-employed (VATs). Aggregation of our data allows us to distinguish, among the broad variety of atypical temporary contracts, nowadays so pervasive in Italy, those involving an employment relationship from autonomous or freelance collaborations. In the first group of atypical contracts we find most of the temporary employment job relationships introduced by the first reforms of the labour market, namely Employee: Temporary contracts (ET), including temporary, work/training, apprenticeship, and work-entry contracts; and Employee: Other-Temporary contracts (EOT), which considers the forms of temporary employment (agency, job sharing, intermittent/on call works, and work practice, internship, traineeship experiences $^{2}$ ) introduced at a later stage. By contrast, the second group of atypical temporary contracts, Autonomous Collaborators $(A C)$, includes the recently introduced forms of temporary autonomous contracts. There are then two residual categories, Employee: Other contracts (EO) and Autonomous: Other contracts (AO), that include people who do not know the contractual form or do not answer the question, respectively in the two broad forms of employment and autonomous work ${ }^{3}$.

Table 3 shows the distribution of our sample of young people among all the possible job arrangements. On average 58\% of our sample (49\% EP and 9\% A) work in typical jobs, while $42 \%$ are found in "atypical" temporary arrangements. Within the latter, 27\% are atypical employees and about $14 \%$ are atypical autonomous collaborators. The total sample consists of an average 2,874 individuals per year, that is $42 \%$ of the total population of young people. Below, the table also reports the status of people belonging to our balanced panel over time. From 2006 to 2010 the percentage of students in our sample quite expectedly decreases, while the percentage of those employed increases. However, since the share of the inactive is almost constant, if the percentage of unemployed decreases from 2006 to 2008 by $1 \%$ in our sample, it increases by about 3\% between 2008 and 2010. As explained in Section 3, AC work arrangements, as well as cases of self-employment with VAT in $A$ might hide de facto employment relationships. Mandrone and Marocco (2012a) have made some attempts in this sense on the ISFOL-PLUS 2010 cross-section, exploiting information on job characteristics that might shed light on the true nature of the work relationships, finding that the incidence of 'false' autonomous is much higher among $A C$ workers, especially if young, than among $A$ workers $(80 \%$ versus $17 \%)$.

\footnotetext{
2 Only paid traineeships, internships and work experience are considered.

${ }^{3}$ See Mandrone (2008) for detailed definitions.
} 
Based on the above considerations, we decided to drop the $A$ workers from our estimation sample, as well as EO and AO, in order to retain only contract types that with a sufficiently high degree of confidence share a de-facto employment relationship. Therefore, we end up using the sample we believe closer to de facto employment, that comprising EP, ET, EOT and AC.

\subsection{Evidence on job satisfaction by contract}

In the ISFOL-PLUS 2006-2008-2010 panel, for all workers job satisfaction is evaluated both overall and in nine dimensions, available as answers to the following questions: "Overall, what is your level of satisfaction with respect to: 1) work environment (relationships with colleagues and superiors); 2) work organisation (timetable, shifts, overtime, holidays); 3) duties; 4) content of job; 5) protection against sickness, accident and industrial injury; 6) career perspectives; 7) pay; 8) competence and skill development; 9) job-stability". Responses were reported at four possible levels, which we re-ordered homogeneously for increasing intensity as follows: low, medium-low, medium-high, high. The 'do not know' and 'not applicable' options were eliminated from the sample.

Table 4 shows how contracts differ across overall job satisfaction and its observed aspects. Columns correspond to a given contract type and show differences in satisfactions between that contract type and $E P$ for each satisfaction category. The last column contains the average satisfactions of $E P$.

We observe significantly lower overall satisfaction levels for EOT and especially AC, while ET workers seem to be close to EP. All categories of atypical workers state they are more satisfied than EP with aspects regarding the development of relationships with colleagues and of skills. Importantly, job security/stability is the only working dimension with which all atypical workers are significantly less satisfied than EP.

Such initial analysis of the data shows that on average 1) young atypical workers are no more satisfied than EP; 2) the primary matter of concern among young atypical workers is job stability. To draw conclusions on differences in job satisfaction across categories of workers, controlling for differences in aspect satisfactions, personal and job characteristics and unobserved heterogeneity along various dimensions, we need to implement an econometric model of perceived satisfaction with appropriate controls and an appropriate error structure. 


\subsection{Explanatory variables}

We use the available information on personal and firms' characteristics. The former group of variables is standard and comprises sex, age, education (3 levels: primary, secondary and tertiary), and region of residence (4 macro-areas: north-west, north-east, centre, south and islands).

The data-set is particularly rich as regards the latter group of variables: we observe occupations (3 groups: high-medium-low skilled), sectors (5 groups: agriculture-forestryfishing, manufacturing, construction, trade and food, services) $)^{4}$, experience, tenure, work place (firm, at home, moving, other people's houses, other firms), firm size, annual earnings, commuting time (in minutes) and over-education (which reports the need/or otherwise of the educational level required for the activity performed).

Table 5 displays the averages for the explanatory variables by contract types in the estimation sample. Individual characteristics are almost equally distributed across contracts. In particular, $60 \%$ of young workers have a medium-level education and only $20 \%$ are highly educated.

Turning to firm characteristics: high-skill occupations are frequently governed by autonomous contracts, whereas in medium-low-skilled occupations employment relationships record the highest frequencies of observations. Also, the occupations where the young work with the highest frequency are medium-high skilled (50\% and 34\%). Sectors that are more intensive in terms of autonomous work are agriculture, construction, trade and food, and services in general, where the majority of young people find occupation. Employment contracts are instead more common in manufacturing. As expected, in EP jobs experience and tenure are higher than in temporary work relationships. The place where the majority of our young workers carry out their activity is the firm. Surprisingly enough, this also holds for AC workers, which indicates the improper use that firms make of these contractual forms for implementing low-cost de-facto employment relationships. Also, the majority of firms using AC would appear to be small.

\section{Econometric strategy}

We observe ten categorical variables of job satisfaction. Let $y_{i t}$ stand for overall job satisfaction and $y_{a, i t}$ for job satisfaction in aspect $a=1, \ldots, 9$ of worker $i=1, \ldots, N$ at time $t=1, \ldots, T$. All satisfaction variables take on values $m=1,2,3,4$, ordered from the lowest to the highest level.

\footnotetext{
${ }^{4}$ Sector (public or private) and Part-time/Full-time controls, although the information is available, were eliminated due to the limited number of observations.
} 
We assume that underlying $y_{i t}$ there is a continuous variable, $y_{i t}^{*}$, thought of as latent job satisfaction, ranging onto the real line, $R$, and that $R$ is partitioned into four intervals common to all individuals $\left(\mu_{m-1}, \mu_{m}\right), m=1,2,3,4$, where $\mu_{0}=-\infty$ and $\mu_{4}=\infty$. Thus, through his/her declared $y_{i t}$, each respondent reveals the interval $\left(\mu_{m(i, t)-1}, \mu_{m(i, t)}\right)$ in which his/her $y_{i t}^{*}$ happens to lie, with $m(i, t)=1,2,3,4$. We then set up a latent regression model for $y_{i t}^{*}$, with five groups of explanatory variables, holding permanent employment, $c=1$, as the reference contract type:

1. The job-aspect satisfactions, $y_{a, i t}, a=1, \ldots, 9$

2. The dummies indicating the three contract types other than permanent, $d_{c, i t}, c=2,3,4$.

3. The interactions of job-aspect satisfactions and contract type indicators, $\left(y_{a} * d_{c}\right)_{i t}$, $a=1, \ldots, 9, c=2,3,4$.

4. Time and regional dummies.

5. The vector $\boldsymbol{x}_{i t}$ of personal and job characteristics indicated in Section 4.

Thus the latent regression model, in its more general form, can be written as

$y_{i t}^{*}=\gamma_{0}+\sum_{a} \gamma_{a} * y_{a, i t}+\sum_{c} \delta_{c} * d_{c, i t}+\sum_{a} \sum_{c} \delta_{a c} *\left(y_{a} * d_{c}\right)_{i t}+\boldsymbol{x}_{i t}^{\prime} * \boldsymbol{\beta}+u_{i t}$

where $u_{i t}=\mu_{i t}+\epsilon_{i t}$ is a composite error comprising possibly correlated effects, $\mu_{i t}$, and an independent idiosyncratic zero-mean component, $\epsilon_{i t}$. More specifically, $\mu_{i t} \equiv \alpha_{i}+$ $\eta_{t}+v_{r(i t)}$, where $\alpha_{i}$ indicates a worker-specific component, which may accommodate, among other individual-specific effects, subjective interpretation of the satisfaction questions; $\eta_{t}$ stands for a time-specific component accommodating aggregate transitory shocks, and $v_{r(i, t)}$ is a regional component capturing latent heterogeneity at the region level, with $r(i, t)$ indicating the region of work for individual $i$ at time $t$.

A less compact but easier to interpret formulation of Equation (1) is one that explicitly represents the four possible job satisfaction statuses for a given worker $i$ at year $t$, depending on his/her contractual arrangement $c(i, t)=c, c=1, \ldots, 4$. Hence 


$$
y_{i t}^{*}=\left\{\begin{array}{l}
\gamma_{0}+\sum_{a=1}^{9} \gamma_{a} * y_{a, i t}+\boldsymbol{x}_{i t}^{\prime} * \boldsymbol{\beta}+u_{i t} \quad \text { if } c(i, t)=1 \\
\gamma_{0}+\delta_{2}+\sum_{a=1}^{9}\left(\gamma_{a}+\delta_{a 2}\right) * y_{a, i t}+\boldsymbol{x}_{i t}^{\prime} * \boldsymbol{\beta}+u_{i t} \text { if } c(i, t)=2 \\
\gamma_{0}+\delta_{3}+\sum_{a=1}^{9}\left(\gamma_{a}+\delta_{a 3}\right) * y_{a, i t}+\boldsymbol{x}_{i t}^{\prime} * \boldsymbol{\beta}+u_{i t} \text { if } c(i, t)=3 \\
\gamma_{0}+\delta_{4}+\sum_{a=1}^{9}\left(\gamma_{a}+\delta_{a 4}\right) * y_{a, i t}+\boldsymbol{x}_{i t}^{\prime} * \boldsymbol{\beta}+u_{i t} \text { if } c(i, t)=4
\end{array}\right.
$$

With the above representation in mind, interpretation of coefficients $\gamma_{0}, \gamma_{a}, \delta_{c}$ and $\delta_{a c}$ is clear-cut.

1. The constant term, $\gamma_{0}$, is the average contribution of all unobserved components, including job aspects, that are peculiar to permanent workers.

2. Coefficients on job-aspect satisfactions, $\gamma_{a}, a=1, \ldots, 9$ are the effects of aspect satisfactions for permanent workers.

3. For a given contract type $c=2,3,4$, coefficient $\delta_{c}$ measures the difference in residual average job satisfaction of that contract type with respect to permanent workers.

4. For a given contract type $c=2,3,4$, coefficients $\delta_{a c}, a=1, \ldots, 9$, measure the differences in aspect satisfaction effects of that contract type with respect to permanent workers.

Our model lends itself to implementing a particular Oaxaca decomposition, where it is only the contribution of the aspect satisfactions to the expected satisfaction gap between two contract types that is decomposed into explained and residual parts ${ }^{5}$. This can be shown as follows. The expected differences in average satisfactions between contract type $c=2,3,4$ and contract type 1 , is decomposed as

$E\left(\bar{y}_{c}^{*}-\bar{y}_{1}^{*} \mid \boldsymbol{x}, \mu\right)=\delta_{c}+\sum_{a=1}^{9} \gamma_{a} *\left(\bar{y}_{c, a}-\bar{y}_{1, a}\right)+\sum_{a=1}^{9} \delta_{a c} * \bar{y}_{c, a}+\left(\overline{\boldsymbol{x}}_{c}-\overline{\boldsymbol{x}}_{1}\right)^{\prime} * \boldsymbol{\beta}+\bar{\mu}_{c}-$ $\bar{\mu}_{1}(2)$

$c=2,3,4$, where $\bar{y}_{c^{\prime}}^{*}, \bar{y}_{c^{\prime}, a}, \overline{\boldsymbol{x}}_{c^{\prime}}$ and $\bar{\mu}_{c^{\prime}}$ indicate the averages of, respectively, $y_{i t}^{*}, y_{a, i t}, \boldsymbol{x}_{i t}$ and $\mu_{i t} \quad$ over all observations $(i, t)$ such that $c(i, t)=c^{\prime}$ and $c^{\prime}=1, \ldots, 4$.

Focusing on the contribution of the aspect satisfactions in Equation (2) we let

${ }^{5}$ A conventional Oaxaca decomposition, in the context of the job satisfaction gaps between non-disabled and disabled workers, is implemented by Pagan and Malo (2009). 
$\Delta S \equiv \delta_{c}+\sum_{a=1}^{9} \gamma_{a} *\left(\bar{y}_{c, a}-\bar{y}_{1, a}\right)+\sum_{a=1}^{9} \delta_{a c} * \bar{y}_{c, a}$.

Since in our data the average difference in the satisfaction for job stability, $\bar{y}_{c, 9}-\bar{y}_{1,9}$, is by far the largest (see Table 4), we rewrite Equation (3) to single out its contribution

$\Delta S \equiv \sum_{a=1}^{8} \gamma_{a} *\left(\bar{y}_{c, a}-\bar{y}_{1, a}\right)+\gamma_{9} *\left(\bar{y}_{c, 9}-\bar{y}_{1,9}\right)+\left(\delta_{c}+\sum_{a=1}^{9} \delta_{a c} * \bar{y}_{c, a}\right)$.

Hence $\Delta S$ comprises:

1. The explained component peculiar to satisfaction for job stability: $\gamma_{9} *\left(\bar{y}_{c, 9}-\bar{y}_{1,9}\right)$;

2. The explained component peculiar to the other job-aspect satisfactions: $\sum_{a=1}^{8} \gamma_{a} *$ $\left(\bar{y}_{c, a}-\bar{y}_{1, a}\right)$

3. The residual contribution of the aspect satisfactions: $\delta_{c}+\sum_{a=1}^{9} \delta_{a c} * \bar{y}_{c, a}$.

We return to Equation (4) and its three components in Subsection 6.3 when we compare the job satisfaction estimates across the contract categories ${ }^{6}$.

Turning to estimation issues, the well-known incidental parameter problem forbids using individual dummies to accommodate the $\alpha$ effects in latent regression models with small clusters of individuals. An alternative solution is to estimate the model parameters by a random effect ordered probit with the $\alpha$ components modelled à la Mundlak, through a linear combination of regressors in group means (Wooldridge 2010). Two other popular methods are both based on the Chamberlain conditional logit estimator, where the $\alpha$ 's are conditioned out in the log-likelihood function: the fixed effect ordered logit minimum distance estimator by Das and Van Soest (1999), and its popular variant by Ferrer-i-Carbonell and Frijter (2004) (adopted by de Graaf Zijl 2012 for a model of job satisfaction similar to ours). All such estimators, however, are computationally expensive, the first involving evaluation of multiple integrals and the last two requiring multiple estimation steps. Moreover, Baetschmann et al. (2011) proved that the various ways through which the Ferrer-i-Carbonell and Frijter (2004) method has been implemented leads to inconsistent estimators.

\footnotetext{
${ }^{6}$ Clearly, a bias of the type documented in Heitmuller (2005) can be found in the total explained and residual components of Equation (2) if $\bar{\mu}_{c}-\bar{\mu}_{1}$ depends on observed variables whose impacts are not identified by the fixed effect estimators. But our interest here centres exclusively on the components of Equation (4), which does not depend on $\bar{\mu}_{c}-\bar{\mu}_{1}$ and as such is consistently estimated, with all its components, by fixed-effect methods.
} 
For all of the above reasons, we follow an alternative estimation strategy based on a fixed effect extension of the linear approach to ordered response models described in Van Praag et al. (2004) and (2006), also known as probit OLS (POLS) (Green and Leeves 2011 use POLS on Australian data). This method is based upon the consideration that ordered probit yields an OLS-like log-likelihood, with the same set of regressors as in the underlying latent regression model and a dependent variable given by the conditional mean $E\left(y_{i t}^{*} \mid \mu_{i t}<y_{i t}^{*} \leq \mu_{i t}\right)$. Then, assuming a standard-normal distribution for $y_{i t}^{*}$, one can estimate $E\left(y_{i t}^{*} \mid \mu_{i t}<y_{i t}^{*} \leq \mu_{i t}\right)$ through sample analogs and implement ordered probit as an OLS regression. In this way the inconsistent estimates of the $\alpha$ elements are separable from the slope estimators, exactly as in ordinary linear panel data models, so that the latter are consistent for $N \rightarrow \infty$ and T fixed.

We implement three different specifications, starting with the most parsimonious one, Model 1, which maintains homogeneous effects of aspect satisfactions across contract types and excludes personal and job controls, setting $\delta_{a c}=0, a=1, \ldots, 9, c=2,3,4$ and $\boldsymbol{\beta}=\mathbf{0}$. Model 2 provides an intermediate specification setting $\boldsymbol{\beta}=\mathbf{0}$, while Model 3 carries out unconstrained estimation. We estimate the three models for the whole sample and, separately, for the male and female subsamples.

A random effect (RE) POLS can always be implemented as an alternative to fixed effect (FE) POLS. Indeed,Van Praag et al. (2004) advocate the use of the former for two reasons: 1) if valid, it is more efficient and 2) it can identify effects of time-constant variables, such as gender. It must be considered, however, that RE POLS is less robust than FE POLS to correlated individual effects. In addition, we prefer to assess the impact of gender at the most general level, by running separate regressions on male and female subsamples. With these pros and cons in mind, we subjected the choice between the two estimators to a battery of heteroskedasticity-robust Hausman tests, which led to rejection of the random effect specification for all models and samples at any conventional level of significance.

Van Praag et al. (2006) show that ordered probit and POLS estimates are almost identical up to a proportionality coefficient. In other words, both methods provide virtually the same estimates of coefficient ratios, referred to as trade-off ratios in Van Praag et al. (2006), in the satisfaction equation. It is not hard to see that the probit analogous of the FE POLS is the RE Ordered Probit à la Mundlak we mentioned above. Therefore, we also applied this estimator to our three models to find that RE POLS estimates and the Mundlak RE Ordered Probit estimates are indeed very close up to a proportionality coefficient with also close t-statistics, exactly as evidenced by Van Praag et al. (2006) in the case of the simple ordered probit and POLS estimates. For example, FE POLS and Mundlak RE Ordered Probit applied to Model 1 
over the whole sample provide an estimate for the trade-off ratio between $y_{1, i t}$ and $y_{2, i t}$ of 3.22 and 3.17, respectively; in Model 2 they both yield a trade-off ratio of 3.03; in Model 3 they yield trade-off ratios of 3.10 and 3.14, respectively. Given this substantial equivalence of results, FE POLS lends itself as a computationally easier alternative to Mundlak RE Ordered Probit. Therefore, we report and comment results exclusively for the former.

\section{Results}

\subsection{Job-aspect satisfactions}

Table 6 shows results for all models and samples. Model 1 assumes homogeneous impacts of job-aspect satisfactions across contract types. As expected, all dimensions of job satisfaction are positively significant. Satisfaction with relationships with colleagues and superiors emerges as the most important determinant of overall job satisfaction, especially for males. Job stability emerges as the second most important dimension of job satisfaction, especially for females.

On comparing our results with previous studies on the subject it has to be borne in mind that we concentrate on the subpopulation of young workers. Nonetheless, our job stability estimate is consistent with the evidence for the UK (Clark, 1997; Green and Heywood, 2011) and Australia (Wooden et al., 2004; Green and Leeves, 2013), where job stability has been found strongly linked to workers' well-being. The data examined by de Graaf-Zijl (2012), instead, tells a different story for the Netherlands, where it is happiness with job content which is the primary aspect and job stability counts for the least. In our data job content has a prominent position only for the male subsample, but in the whole sample, as well as the female sample, it seems to be less important than both relations with colleagues and job stability. Such discrepancy with de Graaf-Zijl (2012) may simply reflect true differences between the populations of Italian young workers and Dutch workers, and indeed be explained by the effective flexicurity policies implemented in the Netherlands. However, since we observe happiness with work relationships, as well as other important dimensions of job satisfaction that instead are not observed in the Dutch data, the job content and the job stability coefficients in de Graaf-Zijl (2012) may also capture the impact of the neglected factors.

After job relationships and job stability, there are the following other job aspects, in order of importance: pay, job content and skills development, and lastly work burden, times and safety. Focussing on contractual dummies, it seems that, ceteris paribus, ET and EOT are more satisfied than EP (especially ET males), whereas AC job satisfaction is not significantly different from EP. The ceteris paribus clause is crucial, since the actual differences in overall 
satisfaction may be mainly driven by differences in aspect satisfactions across contract categories. We return to this in Subsection 6.3.

Model 2 includes interaction terms, allowing for separate effects of aspect satisfaction across contract types. Interestingly, while the interaction terms are jointly significant, contract dummies are no longer so, indicating that, once interactions are included, there are no residual unobserved job aspects to explain differences in overall satisfaction across contract types. Not only does this make interpretation of results more clear-cut, but it is also reassuring in terms of our model specification, which indeed considers a more complete list of aspect satisfactions than in previous studies. For example, de Graaf Zijl (2012) notices that significant coefficients on contract dummies may be explained by turning to neglected job aspects, such as career opportunities and relationships with co-workers, which are instead observed in our analysis. Coefficient estimates on job-aspect satisfaction are still significantly positive and close to those of Model 1.

To fully evaluate the impact of the different domains of satisfaction in Model 2 we also have to consider interaction coefficients, which permit heterogeneous impacts across contract types. ET workers seem to be rather homogeneous to EP over almost all job aspects. Heterogeneity of behaviour with respect to EP seems to characterise EOT and AC to a greater extent, but often with opposite patterns.

Model 3 adds personal and job characteristics to Model 2. Before discussing results for this model we observe, as a result of an $\mathrm{F}$ test, that such additional regressors are not jointly significant, which validates the conclusions already drawn for Model 2. In fact, coefficient estimates here are very close in size to those of Model 2, and have almost always the same sign. The pattern of statistical significance is also confirmed, with one interesting additional result: the positive impact of career satisfaction for ET in the whole sample reaches $10 \%$ significance, where the same coefficient in Model 2 presents a larger standard error.

\subsection{Time, regional and gender effects}

The year 2008 brought about a significantly lower job satisfaction level, compared to 2006 and 2010, for all samples and models. This can be explained with the worsening of expectations in all categories of workers in the wake of the first year of financial crisis in Europe. The fact that, in 2010, job satisfaction reverted, on average, to the levels of 2006, while the Italian youth unemployment rate has increased by 6.5 percentage points from 2008 to 2010 , seems to be puzzling. One possible explanation is that those remaining employed in 
2010, in spite of a worsening macroeconomic background, are relieved that they are able to keep their jobs in bad times, and so upgrade their current expectations compared to 2008.

In models with fixed effects, regional effects are identified by movers across regions, but transition frequencies are extremely low in our data, explaining the general insignificant coefficients on regional dummies.

Male and female intercept estimates reflect average estimated fixed effects for each subsample. Although their differences are not highly significant (based on coefficient and standard error estimates in Table 6, we find that Model 3 yields the highest t-test of -1.57), we observe that the intercept of males is always smaller than that of females, confirming the gender effect evidenced in the literature (this is the "gender paradox" discussed in Section 2).

\subsection{Predicted satisfaction levels}

As observed in Section 4 aspect satisfactions are significantly different across the different types of workers and indeed may explain a great deal of variation in overall job satisfaction among contract types. We now apply our estimation results to bring comparisons to a more factual level, based on the observed patterns of aspect satisfaction. To this end, we rely on Equation (4) in Section 5, a special Oaxaca decomposition of the gap in average job satisfaction between flexible workers and permanent workers, which keeps personal and job characteristics, as well as individual, time and regional effects constant. Table 8 shows estimates of the satisfaction gap, $\Delta S$, and its three components: the explained contributions of 1) the difference in average satisfaction for job stability, which emerges from the analysis of Section 4 as the most prominent concern for all categories of flexible contracts; 2) the differences in the remaining average job-aspect satisfactions; and the residual contribution of 3) the contract-specific coefficients on contract dummies and interactions. We find the following:

1. There are no significant differences between ET and EP both in the whole sample and the female subsample. Restricting to males, instead, we see that ET gain a significantly higher job satisfaction than EP. Significant satisfaction differences are never observed for EOT. At the other extreme, AC workers always have significantly lower job satisfaction than EP.

2. For all categories and all estimation samples lower satisfaction with job stability emerges as the strongest cause of lower overall job satisfaction.

3. In the case of ET, this negative effect is offset by the joint effect of differences in other aspect satisfactions, which is always positive and statistically significant. For 
male ET there is the additional effect of a significantly positive portion of higher job satisfaction brought about by differences in coefficients, which eventually bring male ET onto a higher level of job satisfaction than male EP.

4. In the case of EOT the last two components are barely individually significant. However, they are always positive, with the last also sizeable, such that the two effects together offset the job-stability component both in size and in statistical significance.

5. For AC the last two components always go hand in hand with the job-stability component, contributing to make AC significantly worse off than EP. Using a similar decomposition, de Graaf Zijl (2012) finds similar results for on-call and agency workers, although in the latter case dissatisfaction with work content is more pronounced than dissatisfaction with job stability.

\subsection{Sample selection and endogeneity}

Since the satisfaction questions are restricted to employees, were the employee status related to the idiosyncratic part of the regressions, our estimates would be affected by an incidentaltruncation bias.

Testing the correlation of the idiosyncratic error with past and future selection is not hard. In all models a battery of simple variable addition tests (see Semykina and Wooldridge 2010) never reject the null of zero correlation between $\epsilon_{i t}$ and past or future realizations of the selection. More specifically, the selection rule $s_{i t}$ is such that $s_{i t}=1$ if individual $i$ is in the sample at time $t$ (has the employee status) and $s_{i t}=0$ otherwise. We estimated equation (1) adding each time a different pattern of selection among the right-hand-side variables: $s_{i t-1}$, $s_{i t+1}, \sum_{r=1}^{t-1} s_{i r}$ and $\sum_{r=t+1}^{T} s_{i r}$. These variables never proved either individually or jointly significant. For example, in Model 1, for the whole sample, the t-test of $s_{i t+1}$ is 1.33 (with a $\mathrm{p}$-value of 0.185$)$, the t-test of $s_{i t-1}=-1.09$ (p-value=0.277), the t-test of $\sum_{r=t+1}^{T} s_{i r}=-0.37$ (p-value $=0.712)$ and the t-test of $\sum_{r=1}^{t-1} s_{i r}=0.37(\mathrm{p}$-value= 0.712). Similar results are obtained for the other models and samples.

Testing for contemporaneous selection is more intricate. For example, implementing the twostep procedure suggested in Semykina and Wooldridge (2010) requires that we take care of the incidental truncation on a subset of right-hand-side variables, specifically the aspect satisfaction variables, the contract indicators and, in models 2 and 3, the interactions between the two groups of variables. In any event, this boils down to an unusually high number of 
potentially endogenous regressors, which should be matched by an equal number of nontruncated excluded instruments, a hard task in our sample.

Aware of the above difficulty, we nonetheless attempted to implement the Semykina and Wooldridge test on our most parsimonious specification, Model 1, using the following instruments: the number of family members, its square, the number of children, the foregoing variables interacted with each of the 24 cohort indicators and with the individual height variable. The t-test for the inverse Mills ratio $2 S L S$ fixed effect estimate is 0.54 (pvalue $=0.586$ ), which supports the absence of a selection bias at any conventional level of significance.

Based on the above findings, we did not attempt to correct our estimate for selection bias. We believe, though, that testing and correcting contemporaneous sample selection in satisfaction models with potentially many endogenous variables deserves further effort in the search for relevant instruments. This will be matter for further research on our part.

\section{Conclusions}

In this chapter we have investigated job quality from the point of view of young Italian workers, using self-declared levels of job satisfaction for a sample of young workers extracted from the ISFOL-panel. We estimated three fixed-effect models of job satisfaction, all including nine aspects of job satisfaction and three contractual dummies for de facto temporary employees, ET, EOT and AC, as explanatory variables. We found that, compared to employment permanent positions (EP), lower satisfaction with job stability is the aspect with the highest negative, and significant, incidence on the job satisfaction of all three categories of de facto temporary employment. We also found that ET present patterns of job satisfaction that are rather homogenous to EP. Heterogeneity of behaviour with respect to EP seems to characterise more EOT and AC, but often with opposite patterns. Finally, we found that, while ET and EOT tend to compensate concerns of job stability with other job aspects, attaining job satisfaction levels not significantly different from EP, AC do not, and so, on average, stand as the least satisfied.

Our fixed effect estimates are robust to endogeneity of aspect satisfactions due to correlation with, and sorting of workers into contracts based on, all observables and time-constant unobservables. We also started to tackle sample selection and endogeneity caused by exits to unemployment and non-activity that may be related to idiosyncratic shocks, an issue that, to our knowledge, has received little attention in the empirical literature on job satisfaction. At 
this stage, based on a battery of selection tests, we found no strong evidence of sample selection bias in our fixed-effect estimates. Further work is needed, though, especially in the search for relevant instruments for testing contemporaneous selection in satisfaction models that, like ours, have potentially many endogenous right-hand-side variables.

A conclusion that can be drawn at this stage is that the picture representing youth temporary employment in Italy as a homogeneous group of precarious workers with low expectations needs to be adjusted. ET and, to a lesser extent, EOT contracts seem to ensure satisfaction patterns comparable to those of permanent workers. This is in accordance also with the evidence based on the INPS archives in Berton et al. (2011), showing that ET and EOT are more likely to upgrade to EP positions than AC.

Our analysis shows that the most disadvantaged category of young workers in Italy is undoubtedly that of AC workers, who are contractually free-lancers, but are mostly used by firms for implementing flexibility at a lower cost than temporary employees, justifying the recent policy concerns raised by such contractual arrangements. However, recent policies have aimed at regulating $\mathrm{AC}$ rather than trying to improve the use of ET and EOT, which instead prove better stepping stones to permanent employment and, according to our study, the most satisfactory type of temporary job for young people in Italy. 


\section{References}

Addabbo, T. and G. Solinas (2012), Non-standard employment and quality of work: toward new forms of measurement, in Addabbo T. and G. Solinas (eds.), Non-standard employment and quality of work: the case of Italy, AIEL Series in Labour Economics, Springer Verlag, Heidelberg.

Allen, J. and R. van der Velden (2001), Educational mismatches versus skill mismatches: effects on Wages, job satisfaction and on-the-job search, Oxford Economic Papers, 53(3), pp. 434-52.

Baetschmann, G., Staub, K. and R. Winkelmann (2011), Consistent estimation of the fixed effects ordered logit model, IZA Discussion Paper no. 5443.

Bardasi, E. and M. Francesconi (2004), The impact of atypical employment on individual wellbeing: evidence from a panel of British workers, Social Science and Medicine, 58 (9), pp. $1671-1688$

Bentolila, S., J. J. Dolado and J. F. Jimeno (2012), Reforming an insider-outsider labor market, IZA Journal of European Labor Studies, 1:4.

Berton, F., Devicienti, F. and L. Pacelli (2011), Are temporary jobs a port of entry into permanent employment? Evidence from matched employer-employee data, International Journal of Manpower, 32(8), pp. 879-899.

Berton, F., Richiardi, M. and S. Sacchi (2009), Flex-insecurity. Perchè in Italia la flessibilità diventa precarietà, Il Mulino, Bologna.

Blanchflower, D. G. (2000), Self-employment in OECD countries, Labour Economics, 7, pp. 471-505.

Blanchflower, D. G. and A. J. Oswald (1999), Well-being, insecurity and the decline of American job satisfaction, presented at the Cornell University conference, May 1999, Dartmouth College, mimeo.

Boeri, T. (2011), Institutional reforms and dualism in European labor markets, in Card, O. and O. Ashenfelter (eds.), Handbook of Labor Economics, Volume 4, Part B, Chap. 13, pp. 11731236.

Booth, A. L., Francesconi, M. and J. Frank (2002), Temporary jobs: stepping stones or dead ends? Economic Journal, 112 (480), pp. F189-F213.

Bradley, D. E. and J. A. Roberts (2004), Self-Employment and job satisfaction: Investigating the role of self-efficacy, depression, and seniority, Journal of Small Business Management, Vol. 42, 1, pp. 37-58.

Bruno, G. S. F., Caroleo F. E. and O. Dessy (2013), Stepping stones versus dead end jobs: Exits from temporary contracts in Italy after the 2003 reform, forthcoming in Rivista Internazionale per le Scienze Sociali, 1.

Clark, A. E. (1996), Job Satisfaction in Britain, British Journal of Industrial Relations, vol. 34, 2, pp. 189-217.

Clark, A. E. and A. J. Oswald (1996), Satisfaction and comparison income, Journal of Public Economics, 69, pp. 57-81. 
Clark, A.E. , A. J. Oswald and P. Warr (1996), Is job satisfaction U-shaped in age?, Journal of Occupational and Organizational Psychology, 60, pp. 57-81.

Clark, A. E. (1997), Job Satisfaction and Gender: Why Are Women So Happy at Work, Labour Economics, 4, pp. 189-217.

Das, M. and A. Van Soest (1996), A panel data model for subjective information on household income growth, Journal of Economic Behavior and Organization, 40, pp. 409-426.

de Graaf-Zijl, M. (2012), Job satisfaction and contingent employment, De Economist, 160, pp. $197-218$.

Elder, S. (2009), ILO school-to-work transitions, International Labour Office, Geneva.

Eurofound (2007), Job satisfaction and labour market mobility, Dublin.

Eurofound (2012), Trends in job quality in Europe, Publications Office of the European Union, Luxembourg.

European Commission (2001), Employment in Europe, Employment and social affairs directorate. Office for Official Publications of the European Union, Luxemburg.

European Commission (2007), Toward common principles of flexicurity: More and better jobs through flexibility and security, Office for Official Publications of the European Communities, Luxemburg.

Ferrer-i-Carbonell, A. and P. Frijters (2004), How important is methodology for the estimates of the determinants of happiness?, The Economic Journal, 114, pp. 641-659.

Freeman, R. (1978), Job satisfaction as an economic variable, American Economic Review, 68 , p. $135-141$.

Gottschalk, P. and T. Maloney (1985), Involuntary terminations, unemployment and job matching: a test of job search theory, Journal of Labor Economics, pp. 109-123.

Green, C. and J. S. Heywood (2011), Flexible contracts and subjective well-being, Economic Inquiry, 49, pp. 716-29.

Green, C. and G. D. Leeves (2013), Job security, financial security and worker well-being. New evidence on the effects of flexible employment, Scottish Journal of Political Economy, Vol. 60, 2, pp. 121-138.

Green, F. (2007), Demanding work: The paradox of job quality in the affluent economy, Princeton University Press, Princeton.

Hamermesh, D. (1997), Economic aspects of job satisfaction, in Ashenfelter, O. and W. Oates (eds.), Essays in Labor market Analysis, Wiley, Oxford.

Heitmüller, A. (2005) "A Note on Decompositions in Fixed Effects Models in the Presence of Time-Invariant Characteristics." IZA DP no. 1886

Jahn, E. J., Riphahn, R. T. and C. Schnabel (2012), "Feature: Flexible forms of employment: boon and bane", The Economic Journal, 122, pp. F115-F124.

Kaiser, L. C (2007), Gender-Job Satisfaction Differences across Europe: An Indicator for Labor Market Modernization, International Journal of Manpower, 28 (1), pp. 75-94. 
Mandrone, E. (2008), La riclassificazione del lavoro tra occupazione standard e atipica: l'indagine Isfol-Plus 2006, Collana studi Isfol n. 2008/1.

Mandrone, E. (ed) (2012), Labour Economics PLUS Empirical Studies, ISFOL Temi e Ricerche n. 3, Rome.

Mandrone, E and M. Marocco (2012a), Atipicità, flessibilità e precarietà: una lettura economica e giuridica attraverso l'indagine ISFOL-PLUS, ISFOL Working Paper.

Mandrone, E and M. Marocco (2012b), L'atipicità e i suoi derivati, www.lavoce.info.

Origo, F. and L. Pagani (2009), Flexicurity and job satisfaction in Europe: The importance of perceived and actual job stability for well-being ay work, Labour Economics, 16(5), pp. 547555.

Oswald, A. J. (1997), Happiness and economic performance, Economic Journal, 107(445), pp. 1815-31.

Pagan, R. and M. A. Malo (2009), Job satisfaction and disability: lower expectations about jobs or a matter of health?, The Spanish Economic Review, 11, pp. 51-74.

Ricardo Pagán · Miguel Ángel Malo

Semykina, A., \& Wooldridge, J. M. (2010). Estimating panel data models in the presence of endogeneity and selection. Journal of Econometrics, 157, 375-380.

Sousa-Poza, A. and Sousa-Poza A. A. (2003), Gender differences in job satisfaction in Great Britain, 1991-2000: permanent or transitory?, Applied Economics Letters, 10(11), pp. 691694.

Van Praag, B. M. S. and A. Ferrer-i-Carbonell (2004), Happiness quantified: A satisfaction calculus approach, Oxford Universty Press, Oxford.

Van Praag, B. M. S. and A. Ferrer-i-Carbonell (2006), An almost integration-free approach to ordered response models, Tibergen Institute Discussion Paper. 2006-047/3.

Van Praag, B. M. S. and A. Ferrer-i-Carbonell (2008), A multi- dimensional approach to subjective poverty', in: Kakwani, N. and J. Silber (eds.), Quantitative Approaches to Multidimensional Poverty Measurement, Palgrave, Macmillan, NY.

Wooden, M. and D. Warren (2004), Non-standard employment and job satisfaction: evidence from the HILDA survey, The Journal of Industrial Relations, 46(3), pp. 275-297.

Wooldridge, J. M. (2010), Econometric Analysis of Cross Section and Panel Data, The MIT Press, Cambridge, MA. 
Table 1: Distribution of the sample (aged between 15 and 35) by sex

\begin{tabular}{|c|c|c|c|}
\hline & 2006 & 2008 & 2010 \\
\hline \multicolumn{4}{|l|}{ WHOLE POPULATION } \\
\hline males & 3,237 & 3,229 & 3,225 \\
\hline$\%$ & 47.81 & 47.74 & 47.72 \\
\hline females & 3,534 & 3,535 & 3,533 \\
\hline$\%$ & 52.19 & 52.26 & 52.28 \\
\hline Total & 6,771 & 6,764 & 6,758 \\
\hline \multicolumn{4}{|l|}{ EMPLOYED } \\
\hline males & 1,179 & 1,666 & 1,874 \\
\hline$\%$ & 55.13 & 55.02 & 54.25 \\
\hline females & 959 & 1,363 & 1,581 \\
\hline$\%$ & 44.87 & 44.98 & 45.75 \\
\hline Total & 2,138 & 3,029 & 3,455 \\
\hline
\end{tabular}


Table 2: Definition of contract aggregates in the ISFOL-PLUS 2006-2008-2010 panel

\begin{tabular}{|c|c|c|}
\hline CONTRACT CATEGORY: & TYPICAL & ATYPICAL \\
\hline 1. EMPLOYEE: PERMANENT (EP) & permanent job & \\
\hline 2. EMPLOYEE: TEMPORARY (ET) & & $\begin{array}{l}\text { temporary job } \\
\text { work and training } \\
\text { apprenticeship } \\
\text { starter contract }\end{array}$ \\
\hline 3. EMPLOYEE: OTHER TEMPORARY (EOT) & & $\begin{array}{l}\text { agency temporary } \\
\text { job sharing/on call } \\
\text { stage } \\
\text { professional training }\end{array}$ \\
\hline 4. AUTONOMOUS (A) & $\begin{array}{l}\text { entrepreneur } \\
\text { cooperative members } \\
\text { self-employed (VAT) } \\
\text { family co-worker }\end{array}$ & \\
\hline 5. AUTONOMOUS COLLABORATORS (AC) & & $\begin{array}{l}\text { contracting job } \\
\text { occasional job } \\
\text { consulting job }\end{array}$ \\
\hline 6. EMPLOYEE: OTHER (EO) & & do not know/do not answer \\
\hline 7. AUTONOMOUS: OTHER (AO) & & $\begin{array}{l}\text { do not know/do not } \\
\text { answer }\end{array}$ \\
\hline
\end{tabular}


Table 3: Distribution of young workers by contract and status

\begin{tabular}{|c|c|c|c|c|}
\hline & 2006 & 2008 & 2010 & (2006-2010 \\
\hline Contract (\%) & & & & (averages) \\
\hline $\mathrm{EP}$ & 48.22 & 48.6 & 50.71 & 49.18 \\
\hline ET & 19.64 & 20.47 & 19.39 & 19.83 \\
\hline EOT & 5.8 & 5.28 & 4.6 & 5.23 \\
\hline A & 8.84 & 9.21 & 10.16 & 9.40 \\
\hline $\mathrm{AC}$ & 13.56 & 12.91 & 11.69 & 12.72 \\
\hline $\mathrm{EO}$ & 3.37 & 1.98 & 2.46 & 2.60 \\
\hline $\mathrm{AO}$ & 0.56 & 1.55 & 0.98 & 1.03 \\
\hline Total & 2,138 & 3,029 & 3,455 & $2,874.00$ \\
\hline \multicolumn{5}{|l|}{ Status (\%) } \\
\hline EMPLOYED & 31.58 & 44.78 & 51.12 & 42.49 \\
\hline UNEMPLOYED & 15.64 & 14.84 & 17.39 & 15.96 \\
\hline INACTIVE & 6.91 & 6.14 & 5.09 & 6.05 \\
\hline STUDENT & 45.87 & 34.24 & 26.4 & 35.50 \\
\hline Total & 6,771 & 6,764 & 6,758 & $6,764.33$ \\
\hline
\end{tabular}

Table 4: Dimensions of job satisfaction by contract

\begin{tabular}{|l|c|c|c|c|}
\hline & ET & EOT & AC & EP \\
\hline JS aspects: & & & & \\
\hline Relationships & $0.11 * * *$ & $0.12 * *$ & $0.12 * * *$ & $3.11 * * *$ \\
\hline Times & -0.01 & -0.07 & 0.01 & $3.10 * * *$ \\
\hline Burden & $0.11 * * *$ & -0.01 & 0.04 & $2.90 * * *$ \\
\hline Content & $0.09 * * *$ & -0.02 & 0.01 & $3.03 * * *$ \\
\hline Safety & 0.02 & -0.05 & $-0.15 * * *$ & $3.11 * * *$ \\
\hline Career & 0.05 & -0.06 & $-0.21 * * *$ & $2.44 * * *$ \\
\hline Pay & 0.03 & $-0.13 *$ & $-0.22 * * *$ & $2.51 * * *$ \\
\hline Skills & $0.14 * * *$ & $0.14 * * *$ & $0.09 * *$ & $2.80 * * *$ \\
\hline Stability & $-0.62 * * *$ & $-1.00 * * *$ & $-1.11 * * *$ & $3.26 * * *$ \\
\hline Overall & -0.03 & $-0.13 * * *$ & $-0.25 * * *$ & $2.97 * * *$ \\
\hline
\end{tabular}

- $\mathrm{p}<0.05 ; * * \mathrm{p}<0.01 ; * * * \mathrm{p}<0.001$ 
Table 5: Summary statistics of explanatory variables by contract

\begin{tabular}{|c|c|c|c|c|}
\hline & EP & ET & EOT & $\mathrm{AC}$ \\
\hline Age & 26.483 & 25.431 & 25.265 & 25.433 \\
\hline \multicolumn{5}{|l|}{ Sex: } \\
\hline Males & 0.368 & 0.357 & 0.350 & 0.350 \\
\hline Females & 0.632 & 0.643 & 0.650 & 0.650 \\
\hline \multicolumn{5}{|l|}{ Education: } \\
\hline Low & 0.211 & 0.224 & 0.236 & 0.227 \\
\hline Medium & 0.593 & 0.580 & 0.584 & 0.577 \\
\hline High & 0.195 & 0.196 & 0.180 & 0.196 \\
\hline Overeducated & 0.528 & 0.566 & 0.580 & 0.575 \\
\hline \multicolumn{5}{|l|}{ Occupation: } \\
\hline High skills & 0.325 & 0.418 & 0.408 & 0.567 \\
\hline Medium skills & 0.568 & 0.490 & 0.499 & 0.396 \\
\hline Low skills & 0.107 & 0.092 & 0.093 & 0.038 \\
\hline \multicolumn{5}{|l|}{ Sector: } \\
\hline Agriculture-Forestry-Fishing & 0.013 & 0.026 & 0.014 & 0.020 \\
\hline Manufacturing & 0.143 & 0.098 & 0.112 & 0.035 \\
\hline Construction & 0.033 & 0.027 & 0.027 & 0.026 \\
\hline Trade and Food & 0.192 & 0.204 & 0.182 & 0.119 \\
\hline Services & 0.619 & 0.646 & 0.665 & 0.799 \\
\hline Experience & 8.612 & 5.153 & 4.813 & 5.226 \\
\hline Tenure & 5.653 & 2.407 & 2.266 & 2.311 \\
\hline \multicolumn{5}{|l|}{ Job Place: } \\
\hline Firm & 0.826 & 0.834 & 0.876 & 0.761 \\
\hline Home & 0.004 & 0.004 & 0.005 & 0.026 \\
\hline Moving & 0.103 & 0.091 & 0.059 & 0.138 \\
\hline Others' house & 0.005 & 0.005 & 0.007 & 0.012 \\
\hline Other firm & 0.063 & 0.066 & 0.054 & 0.063 \\
\hline Size & 418.654 & 203.280 & 207.577 & 110.938 \\
\hline Annual earnings & 18764.330 & 16563.340 & 15015.370 & 12167.320 \\
\hline Commuting time & 19.897 & 21.571 & 21.901 & 23.149 \\
\hline Unsafe job & 0.237 & 0.216 & 0.169 & 0.183 \\
\hline
\end{tabular}


Table 6: Job Satisfaction - Fixed effects POLS

\begin{tabular}{|c|c|c|c|c|c|c|c|c|c|}
\hline & \multicolumn{3}{|c|}{ Model 1} & \multicolumn{3}{|c|}{ Model 2} & \multicolumn{3}{|c|}{ Model 3} \\
\hline VARIABLES & Whole sample & Males & Females & Whole sample & Males & Females & Whole sample & Males & Females \\
\hline sat relationships & 0.194**** & $0.208 * * *$ & 0.182 **** & $0.202 * * * *$ & $0.205^{* * * *} *$ & $0.196^{* * * *}$ & $0.204 * * *$ & $0.208 * * *$ & $0.198 * * *$ \\
\hline sat times & $0.0603 * * *$ & $0.0500 *$ & $0.0678 * * *$ & $0.0665 * * *$ & $0.0611 *$ & $0.0710^{* * *}$ & $0.0650 * * *$ & $0.0608 *$ & $0.0723 * *$ \\
\hline sat burden & $0.0694 * * *$ & $0.0614^{* *}$ & $0.0779 * * *$ & $0.0709 * * *$ & 0.0499 & $0.0874 * * *$ & $0.0727 * * *$ & 0.0542 & $0.0881 * * *$ \\
\hline sat content & $0.137 * * *$ & $0.203 * * *$ & $0.0918 * * *$ & $0.124 * * *$ & 0.197 *** & $0.0688^{* * *}$ & $0.123 * * *$ & $0.192 * * *$ & $0.0675^{*}$ \\
\hline sat safety & 0.0386 *** & $0.0412 * *$ & $0.0374 * *$ & $0.0282 *$ & 0.0238 & $0.0348^{*}$ & $0.0298^{*}$ & 0.0248 & 0.0342 \\
\hline sat career & $0.110^{* * * *}$ & $0.143 * * *$ & $0.0867 * * *$ & $0.0844 * * *$ & $0.116^{* * * *}$ & 0.0637 **** & $0.0803 * * *$ & $0.111 * * *$ & $0.0612 * * *$ \\
\hline sat pay & $0.140^{* * * *}$ & $0.121 * * *$ & $0.156^{* * * *}$ & 0.150 **** & $0.154 * * *$ & $0.148^{* * * *}$ & $0.149 * * *$ & $0.159 * * *$ & $0.144 * * *$ \\
\hline sat skills & $0.114 * * *$ & $0.105 * * *$ & $0.119^{* * * *}$ & $0.130 * * *$ & $0.138 * * *$ & $0.119^{* * *} *$ & $0.129 * * *$ & $0.130 * * *$ & $0.124 * * *$ \\
\hline sat stability & $0.166^{* * * *}$ & $0.132 * * *$ & $0.186^{* * * *}$ & $0.150 * * *$ & $0.114^{* * * *}$ & 0.174 *** & $0.147 * * *$ & $0.109 * * *$ & $0.174 * * *$ \\
\hline Ref. PE & & & & & & & & & \\
\hline ET & $0.0753^{* *}$ & $0.113 * *$ & 0.0315 & 0.123 & 0.0566 & 0.0911 & 0.137 & 0.0785 & 0.113 \\
\hline EOT & $0.131 *$ & 0.121 & 0.107 & -0.354 & -0.111 & -0.576 & -0.447 & -0.302 & -0.537 \\
\hline $\mathrm{AC}$ & -0.00978 & -0.0211 & -0.00560 & -0.244 & 0.0598 & $\begin{array}{l}-0.478 \\
\end{array}$ & -0.205 & 0.0752 & -0.385 \\
\hline Controls & no & no & no & no & no & no & yes & yes & yes \\
\hline ET*relationships & & & & 0.0114 & 0.0643 & -0.0288 & 0.0130 & 0.0590 & -0.0265 \\
\hline EOT*relationships & & & & -0.0800 & -0.131 & -0.0718 & -0.0494 & -0.0884 & -0.0503 \\
\hline AC*relationships & & & & -0.0504 & -0.0910 & -0.0258 & -0.0613 & -0.101 & -0.0463 \\
\hline ET*times & & & & -0.00235 & -0.0405 & 0.0219 & -0.000692 & -0.0340 & 0.0178 \\
\hline EOT*times & & & & $0.174 * *$ & 0.232 & 0.152 & $0.179 * *$ & 0.224 & 0.135 \\
\hline AC*times & & & & $-0.105 * *$ & -0.0814 & $-0.118^{*}$ & $-0.101 *$ & -0.0979 & $-0.111 *$ \\
\hline ET* burden & & & & -0.00128 & 0.0506 & -0.0310 & -0.00447 & 0.0475 & -0.0123 \\
\hline EOT* burden & & & & -0.0767 & $-0.268 *$ & 0.00539 & -0.0616 & -0.206 & -0.00791 \\
\hline $\mathrm{AC}^{*}$ burden & & & & 0.0446 & 0.0947 & 0.0109 & 0.0406 & 0.109 & 0.00491 \\
\hline ET*content & & & & 0.00551 & 0.0344 & -0.0133 & 0.00759 & 0.0252 & -0.00626 \\
\hline EOT* content & & & & $0.288 * *$ & $0.343 * *$ & $0.258^{*}$ & $0.269 * *$ & 0.267 & $0.268^{*}$ \\
\hline $\mathrm{AC}^{*}$ content & & & & -0.0263 & $-0.252 * *$ & 0.109 & -0.0252 & $-0.246 * *$ & 0.105 \\
\hline ET*safety & & & & -0.0100 & 0.0167 & -0.0307 & -0.0125 & 0.0186 & -0.0370 \\
\hline EOT* safety & & & & -0.000244 & 0.0152 & 0.0521 & 0.0242 & 0.0378 & 0.0707 \\
\hline AC* safety & & & & 0.0651 & $0.153 * *$ & 0.0199 & 0.0621 & $0.149 * *$ & 0.0212 \\
\hline ET*career & & & & 0.0554 & 0.0401 & 0.0467 & $0.0607^{*}$ & 0.0419 & 0.0518 \\
\hline EOT* career & & & & 0.123 & 0.143 & 0.0544 & 0.118 & 0.128 & 0.0765 \\
\hline $\mathrm{AC}^{*}$ career & & & & $0.0839 *$ & 0.0696 & $0.105^{*}$ & $0.0871^{*}$ & 0.0719 & 0.0994 \\
\hline ET*pay & & & & -0.0541 & $-0.105 *$ & 0.00895 & -0.0592 & $-0.119^{*}$ & 0.00886 \\
\hline
\end{tabular}




\begin{tabular}{|c|c|c|c|c|c|c|c|c|c|}
\hline EOT* pay $^{*}$ & & & & -0.113 & $\begin{array}{c}-0.190 * \\
\end{array}$ & -0.0616 & $-0.132 *$ & -0.175 & -0.0922 \\
\hline AC* pay & & & & 0.0743 & 0.0461 & 0.101 & 0.0716 & 0.0654 & 0.0917 \\
\hline ET*skills & & & & -0.0656 & -0.0932 & -0.0283 & -0.0729 & -0.0873 & -0.0479 \\
\hline EOT* skills & & & & -0.151 & -0.154 & -0.118 & -0.162 & -0.165 & -0.119 \\
\hline AC* skills & & & & 0.0250 & 0.0345 & 0.0188 & 0.0279 & 0.0131 & 0.0318 \\
\hline ET*stability & & & & 0.0455 & 0.0302 & 0.0514 & 0.0470 & 0.0434 & 0.0371 \\
\hline EOT* stability & & & & -0.0185 & 0.0548 & -0.0558 & -0.0137 & 0.0963 & -0.0807 \\
\hline AC* stability & & & & 0.00272 & 0.0314 & -0.0265 & -0.00156 & 0.0395 & -0.0344 \\
\hline Ref. North West & & & & & & & & & \\
\hline North - East & -0.210 & 0.301 & -0.779 & -0.130 & $0.390 *$ & -0.693 & -0.131 & $0.420 *$ & -0.618 \\
\hline Center & 0.397 & -0.240 & 0.855 & 0.330 & -0.245 & 0.660 & 0.309 & -0.211 & 0.633 \\
\hline South-Isles & -0.293 & $-0.603 *$ & 0.0178 & -0.305 & $-0.461 *$ & -0.0709 & -0.301 & $-0.513 *$ & -0.131 \\
\hline Ref. 2006 & & & & & & & & & \\
\hline 2008 & $-0.0842 * * *$ & $-0.0689 * *$ & $-0.0922 * * *$ & -0.0878 **** & $-0.0743 * *$ & $-0.0894 * * *$ & $-0.103 * * *$ & $-0.103 * * *$ & $-0.0928 * * *$ \\
\hline 2010 & 0.0220 & 0.0327 & 0.00977 & 0.0199 & 0.0345 & 0.00943 & - & - & - \\
\hline Constant & $-2.916 * * *$ & $-2.995 * * *$ & $-2.817 * * *$ & $-2.845 * * *$ & $-3.012 * * *$ & $-2.667 * * *$ & $-3.349 * * *$ & $-4.802 * * *$ & $-2.640 * * *$ \\
\hline Observations & 6,860 & 2,827 & 4,033 & 6,860 & 2,827 & 4,033 & 6,794 & 2,804 & 3,990 \\
\hline R-squared & 0.316 & 0.346 & 0.302 & 0.326 & 0.365 & 0.315 & 0.330 & 0.372 & 0.320 \\
\hline Individuals & 3,469 & 1,395 & 2,074 & 3,469 & 1,395 & 2,074 & 3,435 & 1,383 & 2,052 \\
\hline F-test ASatisf ${ }^{8}$ & 0.000 & 0.000 & 0.000 & 0.000 & 0.000 & 0.000 & 0.000 & 0.000 & 0.000 \\
\hline F-test Contracts ${ }^{\S}$ & 0.048 & 0.086 & 0.628 & 0.400 & 0.991 & 0.181 & 0.336 & 0.943 & 0.296 \\
\hline F-test interactions ${ }^{\S}$ & - & - & - & 0.016 & 0.046 & 0.062 & 0.012 & 0.073 & 0.096 \\
\hline F-test X p-value ${ }^{\&}$ & - & - & - & - & - & - & 0.495 & 0.255 & 0.741 \\
\hline
\end{tabular}

Cluster $* * * \mathrm{p}<0.01, * * \mathrm{p}<0.05, * \mathrm{p}<0.1$

$\S$ p-values 
Table 7. Average differences in satisfaction with respect to PE

(Equation (4) decomposition - based on Model 3 estimates for constant personal and job characteristics)

\begin{tabular}{lcccc} 
& ET & EOT & AC \\
\hline \multicolumn{1}{c}{ Whole sample } & & & \\
Difference in job satisfaction $^{1}$ & 0.036 & -0.033 & $-0.230^{* * *}$ \\
due to differences in satisfaction with security $^{2}$ & $-0.091^{* * *}$ & $-0.147 * * *$ & $-0.163^{* * *}$ \\
due to differences in other aspect satisfaction $\mathrm{y}^{3}$ & $0.068^{* * *}$ & $0.011^{*}$ & $-0.013^{*}$ \\
due to differences in coefficients $^{4}$ & 0.059 & 0.104 & -0.053
\end{tabular}

Males

\begin{tabular}{|c|c|c|c|}
\hline Difference in job satisfaction & $0.116^{* *}$ & -0.070 & $-0.226 * * *$ \\
\hline due to differences in satisfaction with security & $-0.054 * * *$ & $-0.103 * * *$ & $-0.113 * * *$ \\
\hline due to differences in other aspect satisfaction & $0.047 * * *$ & 0.001 & $-0.025^{*}$ \\
\hline due to differences in coefficients & $0.123 * *$ & 0.032 & -0.088 \\
\hline
\end{tabular}

Females

$\begin{array}{lccc}\text { Difference in job satisfaction } & 0.033 & -0.023 & -0.243 * * * \\ \text { due to differences in satisfaction with security } & -0.123 * * * & -0.181 * * * & -0.202 * * * \\ \text { due to differences in other aspect satisfaction } & 0.079 * * * & 0.010 & -0.009 \\ \text { due to differences in coefficients } & 0.012 & 0.148 & -0.032\end{array}$

$* * * \mathrm{p}<0.01, * * \mathrm{p}<0.05, * \mathrm{p}<0.1$

${ }^{1} \Delta S .{ }^{2} \gamma_{9} *\left(\bar{y}_{c, 9}-\bar{y}_{1,9}\right) \cdot{ }^{3} \sum_{a=1}^{8} \gamma_{a} *\left(\bar{y}_{c, a}-\bar{y}_{l, a}\right) .{ }^{4} \delta_{c}+\sum_{a=1}^{9} \delta_{a c} * \bar{y}_{c, a}$. 